\title{
ROLE OF SCENARIO PLANNING AND PROBABILITIES IN ECONOMIC DECISION PROBLEMS - LITERATURE REVIEW AND NEW CONCLUSIONS
}

\author{
Helena GASPARS-WIELOCH (D* \\ Department of Operations Research, Faculty of Informatics and Electronic Economy, \\ Poznan University of Economics and Business, Al. Niepodleglosci 10, 61-875, Poznań, Poland \\ *E-mail: helena.gaspars@ue.poznan.pl
}

\begin{abstract}
Purpose - scenario planning is very helpful when the decision maker deals with uncertain issues. Probabilities are also frequently applied to such problems. In the paper, we examine the correctness of combining probabilities with scenario planning in economic decisions which are usually made under uncertainty. The goal of the article is to find and discuss cases where the use of probabilities in scenario planning is appropriate and cases where such an approach is not desirable.
\end{abstract}

Research methodology - in order to achieve this target, we first make a concise literature review of existing approaches concerning the application of probabilities to scenario planning. Then, we investigate and compare diverse decision making circumstances presented by means of numerical examples and differing from each other with regard to the nature of the decision problem (way of payoff estimation, novelty degree of the problem, access to historical data etc.) and the decision maker's objectives and preferences (one-shot or multi-shots decisions, attitude towards risk). We explore the newsvendor problem, the spare parts quantity problem, the project selection problem and the project time management with scenario-based decision project graphs.

Findings - the work contains both recommendations already described in the literature and suggestions formulated by the author. We get to the point that scenario planning is unquestionable support for decision making under uncertainty, however, the use of probabilities as an accompanying tool may be necessary and justified in some specific cases only. Their significance depends for instance on (1) the number of times a given variant is supposed to be executed; (2) the decision maker's knowledge about the considered problem; (3) the novelty degree of the problem; (4) the decision maker's conviction that the probability values really reflect his/her attitude towards risk. The analysis of numerical examples leads us to the conclusion that scenario planning should not be linked with the likelihood (1) for one-shot decisions problems; (2) for decision problems related to different kinds of innovation; (3) in the case of lack of certainty which type of probability definition ought to be applied to a given situation; (4) if the decision maker anticipates new future factors not included in historical data.

Research limitations - in the paper we mainly analyse one-criterion problems and payoff matrices with data precisely defined. Further conclusions can be obtained after investigating multi-criteria cases and examples with interval payoffs. We limit our research to selected probability definitions. Nevertheless, a wider review can lead to new interesting observations.

Practical implications - the aforementioned findings are crucial in such domains as economic modeling and decision theory. The results of the research can be used in planning, management, and decision optimization. They provide valuable guidelines for each decision maker dealing with an uncertain future.

Originality/Value - authors of previous papers related to this topic have already formulated many significant conclusions. However, this contribution examines the problem from a new point of view since it concentrates on novel decisions, concerning unique, innovative or innovation projects (products). It encourages the decision makers to treat problems usually called in the literature "stochastic problems" (i.e. with known probability distribution) as "strategic problems" (i.e. with unknown probability distribution). This is especially the case of the newsvendor problem and the spare parts quantity problem.

Keywords: scenario planning, probabilities, payoff matrix, uncertainty, innovation, decision maker's preferences, economic decisions.

JEL Classification: C44, D81, O31, C02.

Conference topic: Contemporary Issues in Economics Engineering.

(C) 2019 Authors. Published by VGTU Press. This is an open-access article distributed under the terms of the Creative Commons Attribution (http://creativecommons.org/licenses/by/4.0/) License, which permits unrestricted use, distribution, and reproduction in any medium, provided the original author and source are credited. 


\section{Introduction}

Scenario planning (SP) is a frequent tool used in the decision-making process. It is very helpful when the decision maker (DM) deals with issues under uncertainty, i.e. situations where at least one parameter of the decision problem is not deterministic (DMU - decision making under uncertainty). The ability to predict future economic events (e.g. sales forecasts) is undoubtedly crucial to the maintenance of successful business activities (Aras, Kocakoc \& Polat, 2017). Probabilities can be also applied to such problems. They facilitate the choice of the final decision variant since they make the uncertainty less "uncertain".

In the paper, we examine the correctness of combining probabilities with scenario planning. We investigate for that purpose various economic decision problems which are usually indeterministic on account of the unknown future phenomena (Vilkkumaa, Liesio, Salo \& Imola-Sheppard, 2018) and ever-changing markets (Aras et al., 2017).

The objective of the contribution is to:

- enumerate circumstances where the use of probabilities in scenario planning is appropriate,

- situations, where we advise one against it.

The article contains both recommendations already described in the literature and suggestions formulated by the author. Therefore, the contribution constitutes a review of opinions on the aforementioned problem, with additional new conclusions.

The research methods supporting the goal achievement involve literature survey, simulations and analysis of diverse case studies. We concentrate on topics related to the newsvendor problem (newsboy problem, perishable problem), the spare parts quantity problem, the project selection and the project time management with scenario-based decision project graphs.

The contribution is a continuation of the topic raised in the article entitled: Should probabilities be used with scenarios? (Millet, 2009) where the author discusses the pros and cons of using probability data in scenario planning. His insights are very interesting and inspiring. The author rather supports combining probabilities with SP. However, it is worth underlining that these issues are the object of interest of many researchers and opinions differ (Grienitz, Hausicke, \& Schmidt, 2014; Mandel \& Wilson, 1993; Michnik, 2013; Montibeller \& Franco, 2010; Probabilities, 1991; Ralston, \& Wilson, 2006; Ramirez \& Selin, 2014; Ravindran, Phillips and Solberg, 1987). They evaluate the role of the probability distribution depending on different aspects (the essence of scenario planning, individual or group decision making; facilitation in decision making, flexibility in decision making, etc.). Their observations are certainly extremely helpful for decision makers, but in this work, we would like to offer also our reflections on that issue by referring to other facets.

The paper is organized as follows. Section 2 presents the essence of scenario planning and its effects, i.e. payoff matrices. Section 3 discusses different probability definitions and their connection with SP, depending on the considered level of uncertainty. Section 4 quotes diverse standpoints on the role of probability in scenario planning. Section 5 analyzes economic decision problems illustrated by means of payoff matrices. We mainly explore problems connected with innovations (Pohulak-Żołędowska, 2016; Vicianova, Jad'ud'ova, Hronec, \& Rolikova, 2017). Conclusions are gathered in the last section.

\section{Scenario planning and payoff matrices}

Durbach and Stewart (2012) prepared an impressive review of possible models, methods and tools supporting uncertain decision making (especially in the context of multi-criteria decision analysis and optimization). In their paper, they describe, among other things, models with explicit risk measures (I), models with fuzzy numbers (II), models using probabilities or probability-like quantities (III) and models with scenarios (IV), but they underline that uncertainties become increasingly so complex that the elicitation of the first three measures becomes operationally difficult for DMs to comprehend and virtually impossible to validate. Therefore, in their opinion, it is useful to construct scenarios describing possible ways in which the future might unfold.

SP constitutes a technique facilitating the identification of uncertain and uncontrolled factors influencing the consequences of chosen strategies. Thus, SP minimizes surprises. Diverse definitions of the term scenario can be found for instance in Chermack, Lynham \& Ruona (2001); Porter (1985); Schwartz (1991). Numerous guidelines concerning a correct scenarios construction are provided in Dominiak (2006), Montibeller and Franco (2010); Pomerol (2001); Ravindran et al. (1987); Schoemaker (1995); The Center for Innovative Leadership (1995), van der Heijden (1960); Wright and Goodwin (1999). Some of the authors state that the events should be "mutually exclusive and collectively exhaustive".

Scenario planning can support companies, scientific communities, futurists, educational institutions, government planners and military analysts (Mietzner \& Reger, 2005). It has application to crisis management and public sphere. SP is eagerly used by project managers since it is comfortable and allows one to analyse a given problem in a more deterministic way (Schoemaker, 1993, 1995) than for example fuzzy numbers or continuous probability distributions (Durbach, 2014). The strength of scenarios is that they do not describe just one future, but that several realisable or desirable futures are placed side by side (multiple futures). SP is an appropriate way to recognise technological discontinuities or disruptive events and include them into long-range planning - as a consequence, the organisation is better prepared to handle new situations and promote proactive leadership initiatives (Mietzner \& Reger, 2005). 
Note that scenario planning has both supporters and opponents. The last ones stress that SP and the selection of suitable participants (experts) are very time-consuming since a deep understanding and knowledge of the field under investigation is absolutely necessary - data and information from different sources have to be collected and interpreted (Mietzner \& Reger, 2005).

The result of the choice made under uncertainty with scenario planning depends on two factors: which decision (alternative, strategy, variant, option, an alternative course of action) will be chosen and which state of nature (event, scenario) will occur (Gaspars-Wieloch, 2015a). That is why the effects of scenario planning can be presented by means of payoff matrices (decision matrices). Table 1 is related to the case where payoffs are given in the form of single, definite numbers (values). On the other hand, Table 2 concerns outcomes given in the form of intervals (Huynh, Hu, Nakamori \& Kreinovich, 2009; Shashikhin, 2004). The second situation is characteristic of a more uncertain background.

Table 1. Payoff matrix with single, definite values for each pair <scenario,strategy> (source: Gaspars-Wieloch, 2018)

\begin{tabular}{|c|c|c|c|c|c|}
\cline { 2 - 6 } \multicolumn{1}{c|}{} & \multicolumn{5}{c|}{ Decisions (Decision maker) } \\
\hline Scenarios (Nature) & $\boldsymbol{A}_{\mathbf{1}}$ & $\ldots$ & $\boldsymbol{A}_{\boldsymbol{j}}$ & $\ldots$ & $\boldsymbol{A}_{\boldsymbol{n}}$ \\
\hline $\boldsymbol{S}_{\mathbf{1}}$ & $a_{1,1}$ & $\ldots$ & $a_{1, j}$ & $\ldots$ & $a_{1, n}$ \\
\hline$\vdots$ & $\vdots$ & $\ddots$ & $\vdots$ & $\ddots$ & $\vdots$ \\
\hline $\boldsymbol{S}_{\boldsymbol{i}}$ & $a_{i, 1}$ & $\ldots$ & $a_{i, j}$ & $\ldots$ & $a_{i, n}$ \\
\hline$\vdots$ & $\vdots$ & $\ddots$ & $\vdots$ & $\ddots$ & $\vdots$ \\
\hline $\boldsymbol{S}_{\boldsymbol{m}}$ & $a_{m, 1}$ & $\ldots$ & $a_{m, j}$ & $\ldots$ & $a_{m, n}$ \\
\hline
\end{tabular}

The interpretation of the symbols used in Tables 1-2 is as follows: $n$ denotes the number of decisions, $m$ is the number of scenarios, $a_{i, j}$ is the payoff gained by the DM if he/she selects decision $A_{j}$ and scenario $S_{i}$ occurs.

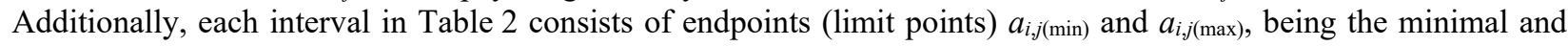
maximal possible outcome. Note that all considered ranges are closed (i.e. both endpoints are included in the intervals).

Table 2. Payoff matrix with interval outcomes for each pair <scenario, strategy $>$ (source: prepared by the author)

\begin{tabular}{|c|c|c|c|c|c|}
\cline { 2 - 6 } \multicolumn{1}{c|}{} & \multicolumn{4}{c|}{ Decisions (Decision maker) } \\
\hline Scenarios (Nature) & $\boldsymbol{A}_{\mathbf{1}}$ & $\ldots$ & $\boldsymbol{A}_{\boldsymbol{j}}$ & $\ldots$ & $\boldsymbol{A}_{\boldsymbol{n}}$ \\
\hline $\boldsymbol{S}_{\mathbf{1}}$ & $<a_{1,1(\min ), a_{1,1(\max )}>}$ & $\ldots$ & $<a_{1, j(\min )}, a_{1, j(\max )}>$ & $\ldots$ & $<a_{1, n(\min ),} a_{1, n(\max )}>$ \\
\hline$\vdots$ & $\vdots$ & $\ddots$ & $\vdots$ & $\ddots$ & $\vdots$ \\
\hline $\boldsymbol{S}_{\boldsymbol{i}}$ & $<a_{i, 1(\min ), a_{i, 1(\max )}>}$ & $\ldots$ & $<a_{i, j(\min )}, a_{i, j(\max )}>$ & $\ldots$ & $<a_{i, n(\min ), a_{i, n(\max )}>}$ \\
\hline$\vdots$ & $\vdots$ & $\ddots$ & $\vdots$ & $\ddots$ & $\vdots$ \\
\hline $\boldsymbol{S}_{\boldsymbol{m}}$ & $<a_{m, 1(\min ), a_{m, 1(\max )}>}$ & $\ldots$ & $<a_{m, j(\min ), a_{m, j(\max )}>}$ & $\ldots$ & $<a_{m, n(\min ), a_{m, n(\max )}>}$ \\
\hline
\end{tabular}

The tables presented above are applied to one-criterion and multi-criteria optimization problem, nevertheless, in the second case, such payoff matrices are required for each target separately.

It is worth emphasizing that the scenario planning stage, which precedes the main step of the decision-making process, can be executed by experts or decision makers (especially for less complex and less complicated decision problems). In the first approach, outcomes are generated in a more objective way. The second one may lead to more subjective estimations (predictions). In both cases, it is recommended to transform initial numbers into values reflecting the decision maker's preferences (utilities) (Ravindran et al., 1987).

\section{Uncertainty levels and probability definitions}

In the previous section the notions uncertainty and uncertain have been mentioned, however it is worth emphasizing that there are four basic degrees (levels) of uncertainty (Cannon \& Kmietowicz, 1974; Courtney, Kirkland \& Viquerie, 1997; Gaspars-Wieloch, 2017a, 2017b, 2019; Guo, 2013, 2014; Haimann, Scott \& Connor, 1985; Kaplan \& Barish, 1967; Kmietowicz \& Pearman, 1984; Knight, 1921; Kofler \& Zweifel, 1993; Larbi, Konieczny \& Marquis, 2010; Ravindran, 2008, Urli \& Nadeau, 2004; Vilkkumaa et el., 2018; Waters, 2011; Weber, 1987). The first one - uncertainty with known probabilities (UKP) - occurs when the decision maker (or expert) is able to set possible scenarios and estimate the likelihood of the occurrence of each state of nature. Technically, it means that Tables 1-2 for UKP contain a supplementary column with probability values. Sometimes, the probability distribution is different for particular decisions and then those tables ought to consist of $2 \times n$ columns). The use of payoffs and probabilities enables one to calculate the expected value. The second level - uncertainty with partially known probabilities (UPKP) - signifies that the decision maker (or expert) is capable of setting possible events and their order, starting with the most probable and ending with the least probable scenario. A partial knowledge may also occur when probabilities are 
presented as intervals (instead of precise values). At the other uncertainty levels, it is assumed that the likelihood is not known. The third level - uncertainty with unknown probabilities (UUP) - concerns cases where the DM (expert) is only able to predict future states of nature, but he/she has no information about the probability distribution. In such a situation the decision maker is allowed to declare his/her attitude towards risk (understood as a possibility that some bad, or other than predicted, circumstances will happen), for example by means of the optimism or pessimism coefficients. According to some approaches, described in the literature, those parameters can be used in order to set probability-like quantities (Gaspars-Wieloch, 2017a). Hence, this time, probabilities are not primary decision problem data they just may be treated as secondary problem parameters. The fourth uncertainty level - total ignorance (TI) - includes all situations where the DM (expert) is not capable of defining future scenarios.

Note that the division of uncertainties presented above is partially consistent with the decision theory and the theory of economics (Gaspars-Wieloch, 2017a; 2017c, 2017d), but it is not the only division suggested in the literature. The necessity to solve decision problems with uncertain parameters led to the development of many other classifications and theories (Zio \& Pedroni, 2013), e.g. probability theory (Kolmogorov, 1933, 1956), possibility theory (Dubois \& Prade, 2001; Zadeh, 1978), imprecise (interval) probability (Walley, 1991), uncertainty theory (Liu, 2007, 2009), credibility theory, evidence theory (Shafer, 1976; Sentz \& Ferson, 2002).

The notion probability has also appeared in the contribution, but it has not been explained yet. As a matter of fact, there are numerous, even contradictory, probability definitions. Generally, the probability is understood as the quality or state of being probable, the extent to which something is likely to happen or be the case. It is the measure of the likelihood that an event will occur. Probability quantifies as a number between 0 and 1, where 0 indicates impossibility and 1 indicates certainty. The probability depends on our knowledge which varies over time. That is why, probability, values are changing over time as well (Caplan, 1999). The most known probability definitions and theories are as follows:

a) classical probability definition (Bernoulli; Laplace, 1812) - the probability of an event is the ratio of the number of cases favourable to it to the number of all cases possible when nothing leads us to expect that any one of these cases should occur more than any other, which renders them, equally possible.

b) geometric probability definition (Leclerc) - the likelihood of hitting a certain area from a given total area (the ratio of the desired area to the total given area).

c) frequentist probability definition ( $\mathrm{R}$. von Mises, 1931, 1957) - the relative frequency of occurrence of an experiment's outcome, when repeating the experiment.

d) prior, posterior (conditional) and inverse probability (Bayes, De Morgan) - the prior probability is assessed before making reference to certain relevant observations; the posterior probability can be assigned after taking into account relevant evidence or background; the inverse probability is the probability of things that are unobserved.

e) propensity probability definition (Popper, 1988) - the probability is the tendency of some experiment to yield a certain outcome, even if it is performed only once.

f) measurable and unmeasurable probability (Knight, 1921) - the first type includes two categories: described (related to our knowledge on the nature of a given object/phenomenon) and experienced (resulting from observed past events) probability; the second type is related to the third category called estimates.

g) Kolmogorov probability theory (Kolmogorov, 1933, 1956) - the first axiom of probability is that the probability of any event is a nonnegative real number, the second axiom is that the probability of the entire sample space is equal to one, the third axiom deals with mutually exclusive events.

h) objective and subjective probability (de Finetti, 1975) - the objective probability is based on a recorded observation or a long history of collected data (random experiments), meanwhile, the subjective probability derives from individual's personal judgment (past experience) and contains no formal calculations.

i) logic probability definition (Carnap, 1950) - probability is a logical relation between two types of statements: the hypothesis (conclusion) and the premises (evidence).

Hence, unfortunately, a unanimous and universal probability interpretation does not exist!

Furthermore, the majority of probability definitions were called into question by a lot of writers (Caplan, 1999, 2001; de Finetti, 1975; Frechet, 1938; L. von Mises, 1949, 1962; Piegat, 2010; Ville, 1939). They are criticised for example for using the word "probable" (see classical probability definition), the lack of a sufficient number of historical data (see frequentist probability definition) and the necessity to use a bounded set of possible events (see geometric probability definition). De Finetti claims that "no matter how much information we have, there is no scientific method to assign a probability to an event" (the probability is just an opinion of a given person) and von Mises even says that the probability calculus has been improperly applied to many scientific disciplines, especially to mathematics. He underlines that the probability of a single event should not be expressed numerically - the mathematical probability of the occurrence of such a scenario is not known since probabilities only concern repetitive situations, meanwhile in many real problems the DMs deal with non-repetitive events! 


\section{Diverse opinions about the role of probability in scenario planning}

It is worth mentioning that scientists declare different opinions concerning the role of probability in scenario planning (Ramirez \& Selin, 2014).

Some of them are convinced that there are many advantages of using objective or subjective probabilities in scenario planning (Millet, 2009; Ravindran et al., 1987). From the point of view of that group, the probability is an inherent element of SP. Millet underlines that it facilitates and improves the whole decision-making process. He supports the use of probabilities in SP as adding much value to events, but he emphasizes that this application is justified, among other things, in the following situations: (1) sufficient time, resources and budget are present to do analytical scenarios with probabilities, (2) the scenario team is familiar and comfortable with the concept of Bayesian probabilities, (3) the corporate culture values quantitative and quasi-quantitative methods while it distrusts purely qualitative reasoning.

Others state that the likelihood should not be applied to SP (Michnik, 2013; Montibeller \& Franco, 2010) as in the case of scenario planning the set of events does not need to be exhaustive, which is the required characteristic of the Kolmogorov theory. Furthermore, Ramirez and Selin (2014) say that "not everything that counts can be counted. (...) While assigning a numerical likelihood for a scenario can be seductive and can ease anxiety, what any form of scenario work seeks is to enhance prospective sense-making. An uncomfortable pause, staying with ambiguity and delving into ignorance may be of more value than a decisive judgement in this regard". Grienitz et al. (2014) suggest developing scenarios without probabilities and focusing on the most important scenario: "From a combinatorial point of view, any given scenario has an infinitesimal probability of being right since there are so many possible variations. (...) When regarding all possible developments that may be relevant for a scenario, each development has only an infinitesimal probability of coming true". This approach is similar to a certain extent with the method described in (Gaspars-Wieloch, 2015b, 2015c), where it is recommended to concentrate on one event or a significantly reduced set of previously expected scenarios. The Shell, SRI International, and GBN scenario practitioners have objected to the use of probabilities for the following reasons: (1) scenarios should be used for identifying possible and preferred futures, not likely futures - all scenarios should be considered equally likely so that plans will be developed for each scenario; (2) the use of probabilities implies too much precision and distracts from the storytelling qualities of scenarios - scenarios are most powerful when they stimulate flexible and innovative thinking about the future; (3) forecasts may capture trends, but they cannot capture the discontinuities of change that come from intuition, imagination and the story qualities of scenarios - the uncertainties of the future are better addressed by multiple and equally plausible scenarios rather than either traditional quantitative forecasts or single "most likely" scenarios; (4) scenarios should be generated by teams, but teams are not able to reach agreement on probabilities of occurrence, so the use of probabilities compromises the team-building benefits (DeGeus, 1988; Fahey \& Randall, 1998; Probabilities, 1991; Mandel \& Wilson, 1993; Ralston \& Wilson, 2006).

As we can see there are supporters and opponents of combining SP with the probabilities and, what is interesting justifications of both groups seem to be rational. The next sections present mainly the author's standpoint (examples are analysed in Section 5 and findings are gathered in Section 6).

\section{Economic decision problems - numerical examples and analysis}

Let us analyse several short numerical examples illustrating economic decision problems. They are connected with the newsvendor problem, the spare parts quantity problem, the project selection, and the project time management with scenario-based decision project graphs, but numerous other applications are also possible, e.g. campaign planning (Kucerova \& Zeman, 2018) or healthcare management (Bahadur \& Shah, 2015).

The first one (I) is related to the single-period spare parts quantity problem (SPQP) - an important element of inventory management, logistics engineering, and supply chain management. SPQP consists of ensuring that the right spare parts and resources are at the right place (where the broken part is) at the right time. Spare parts are kept in an inventory and should be in proximity to a functional item (engine, device, automobile, boat, machine) since they might be used to repair it or to replace failed units. The goal of SPQP is to find the optimal number of extra parts (q) bought with the purchase of the whole device, i.e. to minimize the expected loss resulting from buying a given number of service parts before potential failures (breakdowns). If we buy too many parts with the whole machine, we lose the money spent on the purchase of those parts. On the other side, if we buy not enough spare parts with the whole item, we lose the difference between the current price of a spare part and the previous price of that part. We assume that the demand (D) for extra parts is a random variable with a known probability distribution since the decision maker has historical data concerning the performance of all former devices. The DM intends to use the selected strategy for one hundred devices. Table 3 presents losses $1(\mathrm{D}, \mathrm{q})$ for different $<$ demand, purchase $>$ situations. They are calculated on the basis of s1 - the unit loss from buying a service part with the whole device (loss due to the excess/surplus/overabundance of spare parts), and s2 - the unit loss from buying an extra part just after the failure (loss due to the shortage of spare parts), see Eq. (1). Losses s1 and s2 depend on two types of costs which are usually known or easy to estimate: $\mathrm{c} 1$ denotes the unit purchase cost of the subassembly together with the purchase of the whole device and $\mathrm{c} 2$ signifies 
the unit purchase cost of the subassembly just after the failure (c2 may be treated as a discounted future cost). In such circumstances the DM can (1) define scenarios very precisely, (2) assign probabilities to these scenarios, (2) evaluate the performance of strategic actions across the scenarios using the expected value, and (4) choose those actions that are expected to perform best. The decision is made for a hundred devices, thus, the probability is applied here to repetitive events. The minimal expected loss is connected with $q=3$ (e.g. 3 boxes) and it equals 4.46 (thousands of Euros). Note that in many situations it is recommended to support the expected value with a second decision criterion, e.g. standard variation (payoff dispersions) or distance between extreme values (Gaspars-Wieloch, 2017b).

$$
l(D, q)=\left\{\begin{array}{lll}
s_{1}(q-D), & \text { if } & q>D \\
0, & \text { if } & q=D . \\
s_{2}(D-q), & \text { if } & q<D
\end{array}\right.
$$

Table 3. Loss matrix (in thousands of Euros) - spare parts quantity problem - case I, $c_{1}=6, c_{2}=10, s_{1}=6, s_{2}=4$ (source: prepared by the author)

\begin{tabular}{|c|c|c|c|c|c|c|}
\cline { 3 - 7 } \multicolumn{2}{c|}{} & \multicolumn{5}{c|}{ Spare parts quantity } \\
\hline Probability & Demand & 0 & 1 & 2 & 3 & 4 \\
\hline 0.03 & 0 & 0 & 6 & 12 & 18 & 24 \\
\hline 0.12 & 1 & 4 & 0 & 6 & 12 & 18 \\
\hline 0.24 & 2 & 8 & 4 & 0 & 6 & 12 \\
\hline 0.35 & 3 & 12 & 8 & 4 & 0 & 6 \\
\hline 0.26 & 4 & 16 & 12 & 8 & 4 & 0 \\
\hline
\end{tabular}

The second case (II) is also related to the single-period spare parts quantity problem, but this time the purchase is made only for one device. Such decisions are named one-shot decisions. One-shot decisions, in contradiction to multi-shots decisions, are selected for just one execution (Guo, 2013, 2014). We assume that the DM is able to estimate probabilities on the basis of historical data. Should he use scenario planning with probabilities? Will they be applied to repetitive events? No - the DM intends to buy repair parts merely for one machine! Hence, even if probability data are available thanks to the analysis of the performance of other analogous devices, it does not mean that we must make use of them. In these new circumstances, they are at least partially redundant.

When comparing the above decision situations we can come to a conclusion that the first one is connected with the class probability and the second one is related to the case probability (L. von Mises, 1949). The second one, in L.von Mises' opinion, cannot be expressed numerically and should not be associated with frequency.

The third case (III) concerns the single-period newsvendor problem, NP (Gaspars-Wieloch, 2017b). It consists of finding the order quantity (q) which maximizes the expected profit. It is a production/procurement problem of a retailer who sells a product under random demand (D) without keeping inventory for future use since it is either impossible or impractical. This is the case for newspapers and perishable food. A similar situation arises when an apparel retailer makes orders at the beginning of the season for a fashion item. Such orders are made for one season (sales time window) only, and any unsold (leftover) items are not kept in inventory to be sold next year. They are rather sold at deep discounts at the end of the season. Thus, in the NP the retailer places an order for a product to his own supplier at the beginning of each period and the quantity procured is used solely to satisfy the demand during the current period. In the NP it is assumed that the DM knows $\mathrm{c} 1$ - the unit production/purchase cost of the product, $\mathrm{c} 2$ - the selling price (full retail price) of this product, and $\mathrm{c} 3$ - the discount price (price of leftover items/salvage value), where $\mathrm{c} 3<\mathrm{c} 1<$ $\mathrm{c} 2$. Values of $\mathrm{c} 1, \mathrm{c} 2, \mathrm{c} 3$ allow one to calculate the unit profit (profit margin) from selling the product at price $\mathrm{c} 2$ : $\mathrm{b}=\mathrm{c} 2-\mathrm{c} 1$, and the unit loss from selling it at price $\mathrm{c} 3$ : $\mathrm{s}=\mathrm{c} 1-\mathrm{c} 3$. Table 4 presents gains $\mathrm{g}(\mathrm{D}, \mathrm{q})$ for different $<$ demand, purchase $>$ situations, see Eq. (2). Additionally, we assume that the considered product is innovative - for instance, it satisfies customers' needs in a new way, it is based on the novel, more-effective technologies (processes) or it satisfies a recently discovered need, it meets new requirements (Frankelius, 2009). That is why the retailer is not capable of estimating the probability demand distribution since neither similar nor analogous products have been sold before. In connection with the lack of historical data, undoubtedly the objective likelihood cannot be computed. Despite the innovative nature of the product, the retailer is able to predict prices c3, c1, c2 and the extreme possible demand quantities. What about subjective probabilities? May they be easy to determine and useful in the decision-making process? If the product is totally new, the DM will not be able to define rather rational subjective probability values. Furthermore, if the product is supposed to be bought only for one season (due to its seasonal nature), the use of a quantitative probability seems not to be appropriate.

$$
g(D, q)= \begin{cases}b \cdot q, & \text { if } q \leq D, \\ b \cdot D-s(q-D), & \text { if } q>D .\end{cases}
$$


Table 4. Profit matrix (in thousands of Euros) - newsvendor problem - case III, $\mathrm{c}_{1}=7, \mathrm{c}_{2}=12, \mathrm{c}_{3}=1, b=5, \mathrm{~s}=6$ (source: prepared by the author)

\begin{tabular}{|c|c|c|c|c|c|}
\cline { 2 - 6 } \multicolumn{1}{c|}{} & \multicolumn{5}{c|}{ Order quantity } \\
\hline Demand & 5 & 6 & 7 & 8 & 9 \\
\hline 5 & 25 & 19 & 13 & 18 & 1 \\
\hline 6 & 25 & 30 & 24 & 29 & 23 \\
\hline 7 & 25 & 30 & 35 & 40 & 34 \\
\hline 8 & 25 & 30 & 35 & 40 & 45 \\
\hline 9 & 25 & 30 & 35 & & 23 \\
\hline
\end{tabular}

Note that NP is usually treated as a problem under uncertainty with known probabilities. Nevertheless, according to Benzion, Cohen \& Shavit (2010), newsvendor theory should not assume that the DM faces a known distribution since in real-life situations the demand distribution is not always known. Additionally, the authors demonstrate that knowing probabilities does not necessarily lead the subject closer (than that one who is unaware of the underlying demand distribution) to the optimal solution or to improve profits (Besbes \& Muharremoglu, 2013).

The fourth case (IV) is connected with the innovation or innovative projects selection where the decision maker is a moderate pessimist. We assume that innovation projects bring new products and new services, while innovative projects are projects managed on the basis of new methods (Spalek, 2016). Both types of projects are the result of new ideas, creative thoughts, new imaginations. This time, the values in the payoff matrix (representing, for instance, annual profits) cannot be computed by means of concrete formulas. Nevertheless, it is possible to estimate them with the aid of experts who take into account diverse factors (political, demographic, economic, etc.). Profits and losses are partially given as interval values because of the very uncertain circumstances (customers' and contractors' reactions are difficult to predict), see Table 5. Unfortunately, the probability calculation is too complex as similar projects have not been realized in the past. Furthermore, project selection problems belong to one-shot decision problems for which the likelihood should not be applied. In order to take the DM's preferences into account his/her attitude towards risk can be expressed for example on the basis of the coefficient of pessimism which is a parameter with values not greater than 1 (radical pessimist) and not lower than zero (radical optimist). This coefficient may be applied to transform initial payoffs into individual utilities (Gaspars-Wieloch, 2015b, 2015c, 2015d, 2016).

Table 5. Profit matrix (in thousands of Euros) - projects selection - case IV (source: prepared by the author)

\begin{tabular}{|c|c|c|c|c|c|}
\cline { 2 - 6 } \multicolumn{1}{c|}{} & \multicolumn{5}{c|}{ Projects } \\
\hline Scenario & $P_{1}$ & $P_{2}$ & $P_{3}$ & $P_{4}$ & $P_{5}$ \\
\hline$S_{1}$ & $<100,120>$ & 250 & $<-50,40>$ & $<0,25>$ & $<5$ \\
\hline$S_{2}$ & $<170,200>$ & 50 & $<0,15>$ & $<325,500>$ & $<15,45>$ \\
\hline$S_{3}$ & $<125,160>$ & $<-10,20>$ & $<0,40>$ & 100 & $<0,15>$ \\
\hline$S_{4}$ & $<-100,-50>$ & 40 & $<70,90>$ & 100 & -160 \\
\hline$S_{5}$ & $<-20,0>$ & 0 & $<140,180>$ & -200 & 190 \\
\hline
\end{tabular}

The last short case (V) is devoted to project time management with scenario-based decision project graphs (Gaspars-Wieloch, 2017c) which enable taking diverse modes of activity execution into account thanks to the use of alternative nodes in the network. Let us assume that the project manager has at his disposal payoff matrices presenting activity durations for different execution modes and states of nature. He also knows the probability values calculated on the basis of historical data describing similar tasks already done during previous projects. At first glance, the project manager could benefit from that knowledge, but if he anticipates some new phenomena which can significantly influence the current trend, those data may become worthless.

Note that the cases presented above are not investigated in a comprehensive way. We just focus on the proper use of probabilities in scenario planning. The methodology enabling the final choice of potential decision variants is not the subject of that research.

\section{Conclusions}

In the paper, we discuss the advantages and disadvantages of using scenario planning in economic decisions. There are usually more pros than cons. SP is eagerly used by project managers since it is comfortable and allows one to analyze a given problem in a more deterministic way than for example fuzzy numbers or continuous probability distributions. We state that it can support diverse domains, such as sales forecasting, projects selection or inventory management, but other fields, not mentioned in the contribution, are possible, too.

We also analyse the necessity of applying probability to scenario planning. We admit that it may computationally improve the decision-making process, but as a matter of fact, probabilities should not be combined with scenario planning in many economic decision problems. 
Firstly, we advise one against the assignment of probabilities to particular states of nature, if they are difficult to estimate due to the lack of experience and insufficient knowledge about a given decision problem. This is the case of innovative products, innovative and innovation projects.

Secondly, we conclude that the use of objective probabilities may be impossible when historical data are not available for forecasting future phenomena via statistical analysis. This is also, at least partially, the case of any decisions connected with innovation. It is worth adding that sometimes the decision maker has got access to historical data concerning similar situations, but he/she is anticipating new future factors which can radically change the trend up to now. Thus, in the aforementioned case, the omission of probabilities computed on the basis of historical data seems to be justified, too.

Thirdly, theoretically, the objective probability estimation without historical data is possible if we apply the propensity probability approach where the likelihood is interpreted as is the tendency of some experiment to yield a certain outcome (even if it is performed only once). Nevertheless, when a given decision problem is characterized by a very high novelty degree, even that probability definition is not helpful.

Fourthly, the next inconvenience connected with the combination of probabilities with SP results from the lack of universal and unanimous probability definition. This situation leads to numerous doubts in the DM's mind. He or she might not be able to choose a proper definition for a given problem.

Fifthly, even if it is possible to estimate the probability distribution somehow, we recommend using such measures as coefficients of pessimism (optimism) in order to generate probability-like quantities. This approach allows one to take into consideration the DM's attitude towards risk and it refers to the subjective probability definition.

Sixthly, we stress that probability estimations are redundant in the case of one-shot decision problems since only one scenario will have the chance to occur. In many real problems the DMs deal with non-repetitive events. This conclusion means that even if the probability distribution is available (see UKP and UPKP - uncertainty with known or partially known probabilities), it does not mean that it must be taken into account. However, it is worth emphasizing that one-shot decisions can be associated with probabilities if they are set on the basis of the propensity theory and the knowledge about the problem is sufficient.

Seventhly, we encourage the decision makers to treat problems usually called in the literature "stochastic problems" (i.e. with known probability distribution) as "strategic problems" (i.e. with unknown probability distribution). The work refers to the newsvendor problem, the spare parts quantity problem, the project selection and the project time management with scenario-based decision project graphs, but that might be also the case, for example, of the securities portfolio optimisation. Conclusions (1), (2) and (6) may be regarded as only partially original, but their originality arises from the conclusion (7).

Additionally, we would like to remind the other writers' opinion according to which probabilities should not be assigned to states of nature since in scenario planning the set of events does not need to be exhaustive, which is the required characteristic of the Kolmogorov probability theory. In practice, the decision maker makes the decision on the basis of a list of scenarios which does not cover the whole sample space! Other authors also stress that scenarios should be treated as possible futures, not likely futures. In their opinion states of nature ought to be generated by teams. Teams are able to reach agreement on possible events, but they are not capable of defining unanimous probabilities of occurrence. In future research, it would be desirable to explore the topic discussed in the paper in the context of multicriteria economic decision analysis. It will certainly lead to new interesting observations.

\section{Funding}

This work was supported by the National Science Center, Poland [grant number 2014/15/D/HS4/00771].

\section{Disclosure statement}

The author has no competing financial, professional or personal interests from other parties.

\section{References}

Aras, S., Kocakoc, I. D., \& Polat, C. (2017). Comparative study on retail sales forecasting between single and combination methods. Journal of Business Economics and Management, 18(5), 803-832. https://doi.org/10.3846/16111699.2017.1367324

Bahadur, L. R., \& Shah, S. H. (2015). Healthcare management in the Indian public sector, International Journal of Economic Policy in Emerging Economies, 8(4), 332-346. https://doi.org/10.1504/IJEPEE.2015.073506

Benzion, U., Cohen, Y., \& Shavit, T. (2010). The newsvendor problem with unknown distribution. Journal of the Operational Research Society, 6(6), 1022-1031. https://doi.org/10.1057/jors.2009.56

Besbes, O., \& Muharremoglu, A. (2013). On implications of censoring demand in the newsvendor problem. Management Science, 59(6), 1407-1424. https://doi.org/10.2139/ssrn.1983270

Cannon, C. M., \& Kmietowicz, Z. W. (1974). Decision theory and incomplete knowledge. Journal of Management Studies, 11(3), 224-232. https://doi.org/10.1111/j.1467-6486.1974.tb00695.x 
Caplan, B. (1999). The Austrian search for realistic foundations. Southern Economic Journal, 65(4), 823-838. https://doi.org/10.2307/1061278

Caplan, B. (2001). Probability, common sense, and realism: A reply to Hulsmann and Block. The Quarterly Journal of Austrian Economics, 4(2), 69-86.

Carnap, R. (1950). Logical foundations of probability. University Press. Chicago. https://doi.org/10.2307/2021419

Chermack, T. J., Lynham, S. A., \& Ruona, W. E. A. (2001). A review of scenario planning literature. Future Research Quarterly, 17(2), 7-31.

Courtney, H., Kirkland, J., \& Viquerie, P. (1997), Strategy under uncertainty. Harvard Business Review, 75(6), 66-79.

DeGeus, A. P. (1988). Planning as learning. Harvard Business Review, 88(2), 70-74.

Dominiak, C. (2006). Multi-criteria decision aid under uncertainty. In T. Trzaskalik (Ed.), Multiple criteria decision making '05 (pp. 63-81). Katowice: The Karol Adamiecki University of Economics in Katowice.

Dubois, D., \& Prade, H. (2001). Possibility theory, probability theory and multiple-valued logics: a clarification. Annals of Mathematics and Artificial Intelligence, 32(1-4), 35-66. https://doi.org/10.1023/A:1016740830286

Dubois, D., \& Prade, H. (2012). Gradualness, uncertainty and bipolarity: making sense of fuzzy sets. Fuzzy Sets and Systems, 192, 3-24. https://doi.org/10.1016/j.fss.2010.11.007

Durbach, I. N. (2014). Outranking under uncertainty using scenarios. European Journal of Operational Research, 232(1), 98-108. https://doi.org/10/1016/j.ejor.2013.06.041

Durbach, I. N., \& Stewart, T. J. (2012). Modeling uncertainty in multi-criteria decision analysis. European Journal of Operational Research, 223(1), 1-14. https://doi.org/10.1016/j.ejor.2012.04.038

Fahey, L., \& Randall, R. M. (1998). Learning from the future. New York: Wiley.

Finetti, B. de (1975). Theory of probability. A critical introductory treatment. London, New York, Sidney, Toronto: John Wiley and Sons. https://doi.org/10.1002/bimj.4710190515

Frankelius, P. (2009). Questioning two myths in innovation literature. The Journal of High Technology Management Research, 20, 40-51. https://doi.org.10.1016/j.hitech.2009.02.002

Frechet, M. (1938). The diverse definitions of probability. Lecture at the Fourth International Congress for the Unity of Science. Erkenntnis.

Gaspars-Wieloch, H. (2015a). A decision rule for uncertain multicriteria mixed decision making based on the coefficient of optimism. Multiple Criteria Decision Making, 10, 32-47. University of Economics in Katowice.

Gaspars-Wieloch, H. (2015b). On a decision rule supported by a forecasting stage based on the decision maker's coefficient of optimism. Central European Journal of Operations Research, 23(3), 579-594. https://doi.org/10.1007/s10100-014-0364-5

Gaspars-Wieloch, H. (2015c). On securities portfolio optimization, preferences, payoff matrix estimation and uncertain mixed decision making. In Scientific Conference Contemporary Issues in Business, Management and Education'2015 (pp. 1-11). Vilnius, Lithuania. https://doi.org/10.3846/cibme.2015.04

Gaspars-Wieloch, H. (2015d). Modifications of the Omega ratio for decision making under uncertainty. Croatian Operational Research Review, 6(1), 181-194. https://doi.org/10.17535/crorr.2015.0015

Gaspars-Wieloch, H. (2016). Resource allocation under complete uncertainty - case of asymmetric payoffs. Organization and Management (Organizacja i Zarządzanie), 96, 247-258.

Gaspars-Wieloch, H. (2017a). A decision rule for uncertain multi-criteria pure decision making and independent criteria. Optimum. Economic Studies, 3(87), 77-92. https://doi.org/10.15290/ose.2017.03.87.06

Gaspars-Wieloch, H. (2017b). Newsvendor problem under complete uncertainty: A case of innovative products. Central European Journal of Operations Research, 25(3), 561-585. https://doi.org/10.1007/s10100-016-0458-3

Gaspars-Wieloch, H. (2017c). Innovative projects scheduling with scenario-based decision project graphs. In Contemporary Issues in Business, Management and Education 2017 - Conference Proceedings (pp. 1-11). VGTU Press. https://doi.org/10.3846/cbme.2017.078

Gaspars-Wieloch, H. (2017d). A decision rule based on goal programming and one-stage models for uncertain multi-criteria mixed decision making and games against nature. Croatian Operational Research Review, 8(1), 61-76. https://doi.org/10.17535/crorr.2017.0004

Gaspars-Wieloch, H. (2018). Podejmowanie decyzji w warunkach niepewności - planowanie scenariuszowe, reguty decyzyjne $i$ wybrane zastosowania ekonomiczne [Decision making under uncertainty - scenario planning, decision rules and selected economic applications]. Poznań Universitety of Economics and Business.

Gaspars-Wieloch, H. (2019). Project Net Present Value estimation under uncertainty. Central European Journal of Operations Research, 27(1), 179-197. https://doi.org/10.1007/s10100-017-0500-0

Grienitz, V., Hausicke, M., \& Schmidt, A. M. (2014). Scenario development without probabilities - focusing on the most important scenario. European Journal of Futures Research, 2(27). https://doi.org/10.1007/s40309-013-0027-0

Guo, P. (2013). One-shot decision making with regret. In IEEE Third International Conference on Information Science and Technology (ICIST) (pp. 493-495). IEEE Computer Society. Yangzhou, China. https://doi.org/10.1109/ICIST.2013.6747596

Guo, P. (2014). One-shot decision theory: A fundamental alternative for decision under uncertainty. In P. Guo \& W. Pedrycz (Eds.), Human-centric decision-making models for social sciences (pp. 33-55). Berlin-Heidelberg: Springer-Verlag. https://doi.org/10.1007/978-3-642-39307-5_2

Haimann, T., Scott, W. G., \& Connor, P. E. (1985). Management. Boston: Houghton Mifflin Company. 
Huynh, V. N., Hu, C., Nakamori, Y., \& Kreinovich, V. (2009). On decision making under interval uncertainty: A new justification of Hurwicz optimism-pessimism approach and its use in group decision making. Proceedings of the $39^{\text {th }}$ International Symposium on Multiple-Valued Logic (ISMVL 2009) (pp. 214-220). Naha, Okinawa, Japan. https://doi.org/10.1109/ISMVL.2009.65

Kaplan, S., \& Barish, N. N. (1967). Decision making allowing for uncertainty of future investment opportunities. Management Science, 13(10), B569-B577. https://doi.org/10.1287/mnsc.13.10.B569

Kmietowicz, Z. W., \& Pearman, A. D. (1984). Decision theory, linear partial information and statistical dominance. Omega, 12, 391-399. https://doi.org/10.1016/0305-0483(84)90075-6

Knight, F. (1921). Risk, uncertainty, profit. Boston: Hart. Schaffner \& Marx, Houghton Mifflin Co.

Kofler, E., \& Zweifel, P. (1993). One-shot decisions under linear partial information. Theory and Decision, 34, 1-20. https://doi.org/10.1007/BF01076102

Kolmogorov, A. N. (1933). Grundbegriffe der Wahrscheinlichkeitsrechnung. Berlin: Julius Springer. https://doi.org/10.1007/9783-642-49888-6

Kolmogorov, A. N. (1956). Foundations of the theory of probability. New York: Chelsea Publishing Company.

Kucerova, V., \& Zeman, J. (2018). Methodology for planning a successful store flyer campaign based on a case study from a Czech retail market. Oeconomia Copernicana, 9(4), 755-779. https://doi.org/10.24136/oc.2018.037

Laplace, P. S. (1812). Théorie analytique des probabilités. Paris: Courcier.

Larbi, R. B., Konieczny, S., \& Marquis, P. (2010). A characterization of optimality criteria for decision making under complete ignorance. Proceedings of the Twelfth International Conference on the Principles of Knowledge Representation and Reasoning (pp. 172-181).

Liu, B. (2007). Uncertainty theory (2 ${ }^{\text {nd }}$ ed.). Berlin: Springer-Verlag. https://doi.org/10.1007/978-3-540-73165-8_5Liu, B. (2009). Some research problems in uncertainty theory. Journal of Uncertain Systems, 3(1), 3-10.

Mandel, T. F., \& Wilson, I. (1993). How companies use scenarios: Practices and prescriptions. SRI International, Business Intelligence Program (Report No. 822).

Michnik, J. (2013). Scenario planning + MCDA procedure for innovation selection problem. Foundations of Computing and Decision Sciences, 38(3), 207-220. https://doi.org/10.2478/fcds-2013-0010

Mietzner, D., \& Reger, G. (2005). Advantages and disadvantages of scenario approaches for strategic foresight. International Journal of Technology Intelligence and Planning, 1(2), 220-239. https://doi.org/10.1504/IJTIP.2005.006516

Millett, S. M. (2009). Should probabilities be used with scenarios? Journal of Futures Studies, 13(4), 61-68.

Mises, L. von (1949). Human action. A treatise on economics. Auburn, Alabama: Ludwig von Mises Institute.

Mises, L. von (1962). The ultimate foundation of economic science. An essay on method. Princeton, New Jersey, Toronto, New York, London: D. van Nostrand Company, Inc.

Mises, R. von (1931). Wahrscheinlichkeitsrechnung und ihre Anwendung in der Statistik und theoretischen Physik. Leipzig, Vienna: Deuticke.

Mises, R. von (1957). Probability, statistics and truth. New York: The Macmillan Company.

Montibeller, G., \& Franco, A. (2010). Multi-criteria decision analysis for strategic decision making. In C. Zopounidis \& P. M. Pardalos (Eds.), Handbook of multicriteria analysis, applied optimization (pp. 25-48). Berlin Heidelberg: SpringerVerlag. https://doi.org/10.1007/978-3-540-92828-7_2

Piegat, A. (2010). Uncertainty of probability. Workshop on Intuitionistic Fuzzy Sets and Generalized Nets. http://www.ibspan.waw.pl/ifs2010

Pohulak-Żołędowska, E. (2016). Innovation in contemporary economies. Oeconomia Copernicana, 7(3), 451-466. https://doi.org/10.12775/OeC.2016.026

Pomerol, J. C. (2001). Scenario development and practical decision making under uncertainty. Decision Support Systems, 31(2), 197-204. https://doi.org/10.1007/s007660050003

Popper, K. R. (1988). The open universe: An argument for indeterminism. Psychology Press.

Porter, M. E. (1985). Competitive advantage. New York: The Free Press.

Probabilities: Help or hindrance in scenario planning? (1991). The deeper news: Exploring future business environment, 2(4), Topic 154. Global Business Network.

Ralston, B., \& Wilson, I. (2006). The scenario planning handbook. Mason, Ohio: Thomson South-Western.

Ramirez, R., \& Selin, C. (2014). Plausibility and probability in scenario planning. Foresight, 16(1), 54-74. https://doi.org/10.1108/FS-08-2012-0061

Ravindran, A. R. (2008). Operations research and management science handbook. Boca Raton, London, New York: CRS Press.

Ravindran, A. R., Phillips, D. T., \& Solberg, J. J. (1987). Operations research: principles and practice (2 ${ }^{\text {nd }}$ ed.). Wiley.

Schoemaker, P. J. H. (1993). Multiple scenario development: Its conceptual and behavioral foundation. Strategic Management Journal, 14(3), 193-213. https://doi.org/10.1002/smj.4250140304

Schoemaker, P. J. H. (1995). Scenario planning: A tool for strategic thinking. Sloan Management Review, 36(2), 25-40.

Schwartz, P. (1991). The art of the long view. New York: Doubleday.

Sentz, K., \& Ferson, S. (2002). Combination of evidence in Dempster-Shafer theory (Sandia Report SAND2002-0835). Albuquerque: Sandia National Laboratories. https://doi.org/10.2172/800792

Shafer, G. (1976). A mathematical theory of evidence. Princeton: Princeton University Press. 
Shashikhin, V. N. (2004). Antagonistic game with interval payoff functions. Cybernetics and Systems Analysis, 40(4), 556-564. https://doi.org/10.1023/B:CASA.0000047877.10921.d0

Spalek, S. (2016). Innovative vs. innovation projects in organisations. In E. Wszendybył Skulska (Ed.), Innowacyjność współczesnych organizacji (pp. 226-237). TNOiK, Torun.

The Center for Innovative Leadership (1995). Strategic management: introduction to scenario thinking public workshop. Rivonia, South Africa.

Urli, B., \& Nadeau, R. (2004). PROMISE/scenarios: An interactive method for multiobjective stochastic linear programming under partial uncertainty. European Journal of Operational Research, 155(2), 361-372. https://doi.org/10.1016/S03772217(02)00859-7

Van der Heijden, K. (1996). Scenarios: The art of strategic conversation. Chichester: John Wiley and Sons.

Vicianova, J. H., Jad'ud'ova, J., Hronec, M., \& Rolikova, S.(2017). Developing eco-innovation in business practice in Slovakia. Journal of Business Economics and Management, 18(5), 1042-1061. https://doi.org/10.3846/16111699.2017.1381146

Vilkkumaa, E., Liesio, J., Salo, A., \& Imola-Sheppard, L. (2018). Scenario-based portfolio model for building robust and proactive strategies. European Journal of Operations Research, 266(1), 205-220. https://doi.org/10.1016/j.ejor.2017.09.012

Ville, J. (1939). Etude critique de la notion collectif. Paris: Librairie Gauthier-Villars.

Walley, P. (1991). Statistical reasoning with imprecise probabilities. Chapman and Hall. https://doi.org/10.1007/978-1-48993472-7

Waters, D. (2011). Supply chain risk management. Vulnerability and resilience in logistics (2 ${ }^{\text {nd }}$ ed.). London: Kogan Page.

Weber, M. (1987). Decision making with incomplete information. European Journal of Operational Research, 28(1), 44-57. https://doi.org/10.1016/0377-2217(87)90168-8

Wright, G., \& Goodwin, P. (1999). Future-focused thinking: combining scenario planning with decision analysis. Journal of Multi-Criteria Decision Analysis, 8, 311-321. https://doi.org/10.1002/1099-1360(199911)8:6<311::AIDMCDA256>3.0.CO;2-T

Zadeh, L. A. (1978). Fuzzy sets as the basis for a theory of possibility. Fuzzy Sets and Systems, 100(1), 9-34. https://doi.org/10.1016/S0165-0114(99)80004-9

Zio, E., \& Pedroni, N. (2013). Literature review of methods for representing uncertainty. Cahiers de la Sécurité Industrielle, 201303, FONCSI. Toulouse, France. http://www.FonCSI.org/en/ 